\title{
Design Consideration for Window Placement to Provide the View within the Patient's Visual Range
}

\author{
Maria Myron Charlotta Sengke ${ }^{1}$, Paramita Atmodiwirjo ${ }^{1 *}$, Yandi Andri Yatmo ${ }^{1}$, Mikhael \\ Johanes $^{2}$ \\ ${ }^{1}$ Department of Architecture, Faculty of Engineering, Universitas Indonesia \\ ${ }^{2}$ École Polytechnique Fédérale de Lausanne, Switzerland \\ I*paramita@eng.ui.ac.id
}

Received: $11^{\text {th }}$ December $2019 \quad$ Final version received: $20^{\text {th }}$ April 2020

This study argues on the importance of considering the visual capacity of the observers in the placement of the windows to provide views to the natural outdoor environment. In particular, this study explores the mechanism of seeing that involves foveal and peripheral view in defining the patients' visual capacity in experiencing the spaces of the healing environment. The placement of windows to connect the inside with the outside becomes irrelevant when their placement is not within the patient's visual range. To examine the patient's view toward the windows, we performed a $3 \mathrm{~d}$ simulation of a hospital inpatient room and captured the scenes representing the foveal and peripheral views of the openings from various positions of bed-ridden patients. The region calculation of the opening elements within the captured image reveals the presence of opening within the peripheral range of patients' view. This study suggests that the design of healing environment should not be based merely on the physical arrangement of interior elements, but should also consider how the elements are experienced within the view of the patient.

Keywords: Seeing, Window View, Foveal, Peripheral, Healing Environment

\section{INTRODUCTION}

This study addresses how the limited visual capacity of the patient needs to be considered in providing the patients with the view of the natural outdoor environment. Research has suggested that the outdoor view has an impact on the patient's healing and recovery process (Waroonkun, 2018). Patients assigned to the room with a windows view tend to experience faster recovery, show fewer complaints, and require fewer doses of the medicine than the patients in the room without a windows view (Ulrich, 1984). However, the presence of the windows in the patient room may become irrelevant when their placement does not consider the real visual experience of the patients. It becomes necessary to consider the arrangement in relation to the patient's seeing capacity (Sengke et al., 2018).

The study on the patient's real visual experience requires the understanding of the seeing mechanism as a way to mediate the gap between the seeing experience and the arrangement of the visual elements in space. This study suggests the shifting paradigm from merely providing visual stimuli for the patient to entering into a patient's visual experience. The shifting paradigm suggests an alternative approach in understanding space; space is no longer seen only as an organization of the interior elements to be seen from various angles (Kleine, 2018), but space becomes meaningful when understood as the arrangement of elements located within the users' visual range. Entering into the visual experience of the viewer can be attempted by capturing the images from the patients' point of view; hence the body and the image-space experienced by the patient becomes a representation of the patient experience (Vall \& Zwijnenberg, 2009; Weigel \& Paul, 2003).

The interior design of the healing environment often demonstrates a lack of attention to the placement of windows as a medium to provide the outdoor view for patients. This leads to a 
question regarding the potential of openings to provide the view for the patients. In particular, this study addresses the questions: How much are the openings visible to the patients as represented by the proportion of area seen within the visual range of patient? And how do the different patients' positions change the visual range?

\subsection{The role of windows in the patient's experience}

Being in a healthcare environment has a potential impact in causing stress to patients (Cervinka et al., 2014). The view through the windows can give a momentary experience of feeling nature and being detached from the hospital setting. The view of nature in the hospital could provide psychological and emotional healing (Helphand, 2019). As also found in many settings such as schools, offices and hospitals, windows can offer psychological benefits, recover stress, and improve peace and calmness (Alam \& Shari, 2019; Hussein, 2009; Jamaludin et al., 2018; Orbon et al., 2019). Research indicates that access to nature view through the windows is the predictor of patients' satisfaction and eventually their health and wellbeing (Hussein, 2009; Malek et al., 2018; Yuniati et al., 2018). The window openness to natural view is related to patients' satisfaction with space, spaciousness and satisfaction (Ozdemir, 2010; Yildirim et al., 2007).

Relation to nature has been found to encourage the patients to maintain self-care behaviour, reduce negative emotions and induce positive emotions (Hunter et al., 2019; Lyons \& Carhart-Harris, 2018). The window views could give positive impact not only psychologically, but also in terms of physical health as proven the effect on the human immune system (Rainey, 2019). Unfortunately, the opportunity to see through the windows is not always present for all patient conditions, thus may create anxiety for the patient. The views are especially important for patients in the bedridden condition who are restricted to stay in the same room and limited in their movement (Ulrich, 1993; Ulrich et al., 2008). The presence of elements that can bring the outside view into the inside becomes crucial for patients with limited mobility.

However, there is a lack of research on how the windows and views of nature are experienced within the patients' visual experience. The above studies tend to suggest the presence of windows to provide the view within the patient's vision. It becomes necessary to understand the seeing mechanism that explains the patient's visual experience and visual capacity and use this understanding as the basis for studying the visual experience of windows from the patients' position. This study argues that by capturing the images from the patient's experience, our approach in designing the arrangement of space elements could become more objective and more meaningful for the patients' healing and recovery process. It becomes necessary to understand the visual experience of patients from the static point of view toward their surrounding environment.

\subsection{Visual capacity in the experience of space: Foveal and peripheral vision}

This study emphasizes the value of the elements in the physical environment that are fit within the range of visual range capacities in the patient's viewing experience. The concept of isovist is used to understand parts of the environment that could be visible from a particular point of view (Turner et al., 2001). A previous study on isovist in healthcare environment indicates the possibility to identify the areas that are visible and not visible for the purpose of monitoring and navigation in the hospital environment (Johanes \& Yatmo, 2018). However, such studies do not consider the limitation of the observer's visual range. It becomes necessary to study the visual experience by understanding the parts that are beyond the visibility area of an environment, thus explaining the relationship of the parts of the interior (Johanes et al., 2015). This research attempts to extend the idea of isovist as the visible area by considering the patient's visual capacity in seeing this visible area. In other words, this study reveals the isovist within the restricted patients' visual range.

The seeing mechanism could be understood based on the field of view from the observer. The field view in general is the same from person to person (Walsh, 2011) however, the lightsensitivity threshold created the limit for the field of view based on the degrees away from the fixation, and this gives the boundary for the field of view depending on the photoreceptor in the retina area. The region of the field of view can be divided into the central area which is called the area of foveal vision and the perifoveal area as the peripheral vision (Remington \& Remington, 2012). 
Several studies have identified the range limit of foveal vision. The foveal vision area is divided into three parts (Chua et al., 2016; Ishiguro \& Rekimoto, 2011). The first part is 4050 as a range that allows the precision reading of the text; the second part is $300-400$ as a range that allows the seeing of a shape of an object. The function of foveal vision is to allow the observer to identify the essential visual element within the visual sphere (Levin et al., 2011). The peripheral vision can also be categories into two parts: the horizontal peripheral vision and the vertical peripheral vision. The horizontal visual range is around $1500-2100$ and the vertical visual range is around 600-750. The vertical visual range consists of the superior area that begins from the horizontal line of sight to the upward sight of 00-600, and the inferior area that begins from the horizontal line of sight to the downward sight of 00-750 (Herman, 2007; Olver et al., 2014). By examining the parts of the environment that are within these ranges, it is possible to identify which elements are within the visual range and which are not.

Both types of vision have an important role in defining the visual experience in an environment. The perception of the physical environment is formed by the integration of foveal and peripheral vision. Foveal vision is more superior in visual acuity due to the pack of photoreceptors in the central retinal area and the higher density of ganglion cells. Compared to peripheral vision the foveal vision allows for better perception of depth in three-dimensional scenes, recognition of complex pattern, and in discrimination tasks based on the high resolution of foveal vision and visuomotor integration (Dagnelie, 2011).

Meanwhile, the peripheral vision has a low visual acuity in obtaining visual information, due to the distribution of the photoreceptors, which are more numerous. Nevertheless, peripheral vision has an important role in providing the experience of interiority in space. There are several strengths of peripheral vision, such as in creating the image of the surrounding world in $2 \mathrm{~d}$ visual and $3 \mathrm{~d}$ visual sphere, allocating the gaze to a spatial position (Hitzel, 2015), locating the fixation target and collecting the foveal attention in visual working memory through multiple fixations (Artal, 2017), and allocating foveal attention based on spatial context in enable to adapt to the changing environment (Suter \& Harvey, 2016).
Understanding the foveal and peripheral views is not enough to establish the spatial experience; it is necessary to integrate a series of views of foveal vision to be connected to one another to form a figure-ground relationship that will set into the elements of peripheral view (Kubovy \& Pomerantz, 2019). The figureground relationship is defined by the principles guiding the configuration of the parts such as size, surrounded, convexity, symmetry and parallel (Handel, 2019).

Dagnelie (2011) believed that it is the foveal vision that provides the focused view that established the visual experience. Foveal vision offers the view of the parts that set up the whole viewing experience. However, peripheral vision has several strengths in such a way that it supports Pallasmaa's argument on the role of the peripheral vision in defining space experience in architecture. The very essence of the lived experience is created by the unfocused peripheral vision, and architectural spaces provide stimuli for peripheral vision and centre us in the space (Pallasmaa, 2012) while the foveal view of the scene restricts the visual experience.

In relation to the current study on the window view for patients, the peripheral vision will lead to patient's seeing experience position as the centre of the environment. However, it is also necessary to explore more to confirm the role of the focus view through the potentiality and the limitation of foveal vision. The study of foveal vision could explain the part of the windows that are within the patient's view. But there is also a need to understand how the visual elements in foveal and peripheral vision are combined to establish a whole seeing experience.

\section{METHODS}

\subsection{Setting of simulation study}

This study was conducted by simulating the patient's seeing experience in a typical inpatient room. The simulated setting is an inpatient room that could accommodate four patients. The arrangement consists of four patients bed, one toilet, curtain rails that divide between patient's beds and other furniture. The dimension of the inpatient room is $6300 \mathrm{~mm}$ width, $6635 \mathrm{~mm}$ length, and $2600 \mathrm{~mm}$ height. The windows view is present on one side of the wall, in the forms of two doors and one window made of transparent glass panels with aluminium frame. 

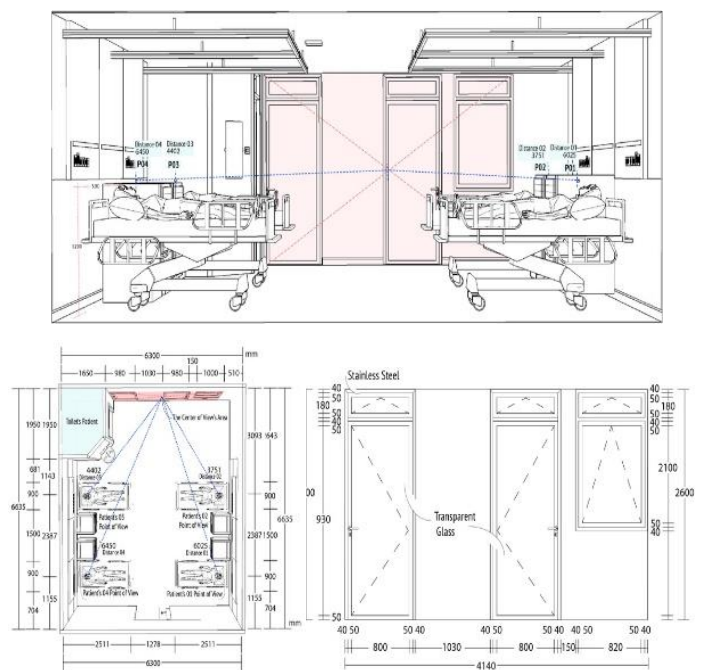

Figure 1: Simulation model of the inpatient room

Source: Authors, 2019

The dimension of each door is $900 \mathrm{~mm}$ wide and 2600 high, while the dimension of the windows is $1000 \mathrm{~mm}$ wide and $1600 \mathrm{~mm}$ high. The total door and windows area is approximately $50 \%$ of the area of the wall where they are attached. There is a patient toilet on the left side of this wall which reduces the area of the wall that could have openings.

\subsection{Simulation procedure: Mapping the patient's visual sphere}

The use of computational medium allows for the visualization of various aspects of spatial configuration that support the performance of healthcare environment (Johanes et al., 2015; Sengke \& Atmodiwirjo, 2017). In this study, the representation of the visual sphere is performed by mapping the $3 \mathrm{~d}$ spherical scene into the $2 \mathrm{~d}$ medium. The visual sphere from a single point of view consists of the scene within the angle of foveal vision and peripheral vision. The series of the scene of foveal and peripheral vision was captured by using the camera view in the Rhinoceros 3d simulation model of the patient's room. The model shows the main architectural and interior elements of the patient room. The camera point is set to simulate the patient's point of view which is assumed to be in lying position on the bed, with the eyepoint at the height of $1200 \mathrm{~mm}$ and the distance from the rear wall was $530 \mathrm{~mm}$.

In this study, the presentation of the mapping coordinate visual system was a stereographic projection from the angle of foveal and peripheral vision. It consists of the combination of the foveal view of $30^{\circ}$ at the horizontal and vertical direction, and the peripheral view that covers the horizontal range of $210^{\circ}$ and the vertical range of $135^{\circ}$, each divided into the segments of $15^{\circ}$, and altogether create the grid of the visual sphere. The camera view was used to capture the scene to represent the eye movement in each of the $15^{\circ}$ segments within these horizontal and vertical range (Figure 2).
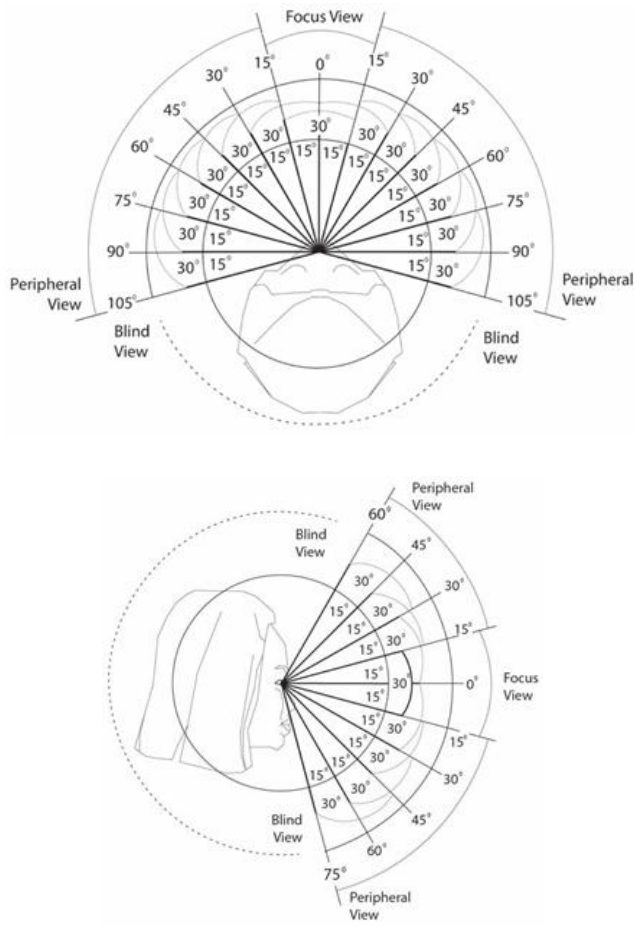

Figure 2: Peripheral and foveal range of view Source: Authors, 2019

The setting of camera view thus produces 13 images in the horizontal direction of the eye movement and eight images in the vertical direction of the eye movement. Altogether the series of horizontal and vertical images create a visual coordinate system mapping based on a projected visual view of the patient's sphere. The horizontal viewpoints are mapped into the $\mathrm{x}$ axis, and the vertical viewpoints are mapped into the $y$-axis in the patient's visual coordinate system.

Based on the mapping of the patients' visual sphere, the calculation of the region of interior elements and the region of the windows view was performed using the MATLAB image region analyzer to calculate the region properties. Before the calculation, the image needs to be transformed into several classes using the image 
segmenter, to represent the parts of the image. into a logical class through the image segmenter, to determine the image in parts. For the purpose of the study, the region calculation was performed in the scene that encompasses the region that represents the pieces of outdoor view, consisting of the door panels, upper door panels, windows panels, and upper windows panels. The calculation resulted in the percentage of the total regions of the elements that represent the total area of outdoor view.
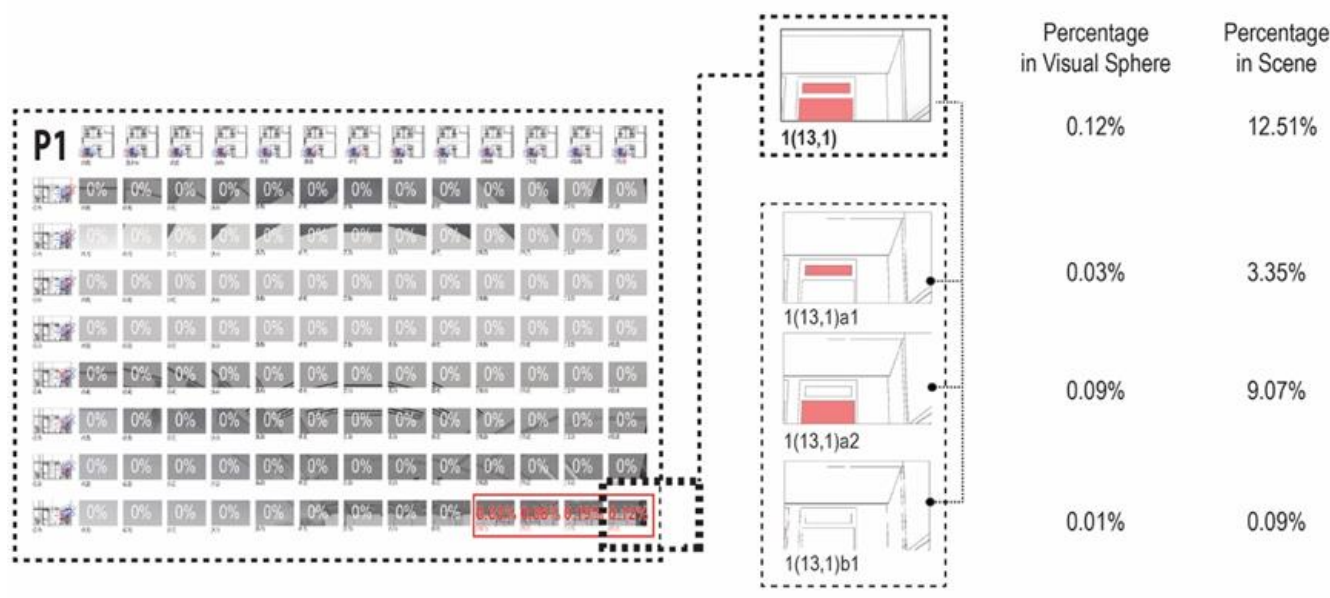

Figure 3: Calculation example of region percentage in visual sphere and in each scene Source: Authors, 2019

\section{RESULTS}

\subsection{Overall visual experience from four patient positions}

Based on the results of the simulation, it was found that from the $100 \%$ visual sphere of the patient, the view area to the openings of doors and windows in the four patients' point of view is within the range of $0.23 \%$ to $1.86 \%$, and all are located within their peripheral view. The patient room has a symmetrical layout in terms of the beds' position. This means that each opposite positions have the mirroring position of the view area in the visual sphere.
As can be seen from Figure 4, the patients positioned on the right side (P1 and $\mathrm{P} 2$ ) have the view area to the openings on the right-downward parts of their visual sphere, which means the openings could only be within their vision when they slightly move their eyes toward the rightdownward direction. Meanwhile, the patients positioned on the left side (P3 and $\mathrm{P} 4)$ have the view area to the openings on the left-downward parts of their visual sphere, which means the openings could only be visible with leftdownward direction of eye movement. 


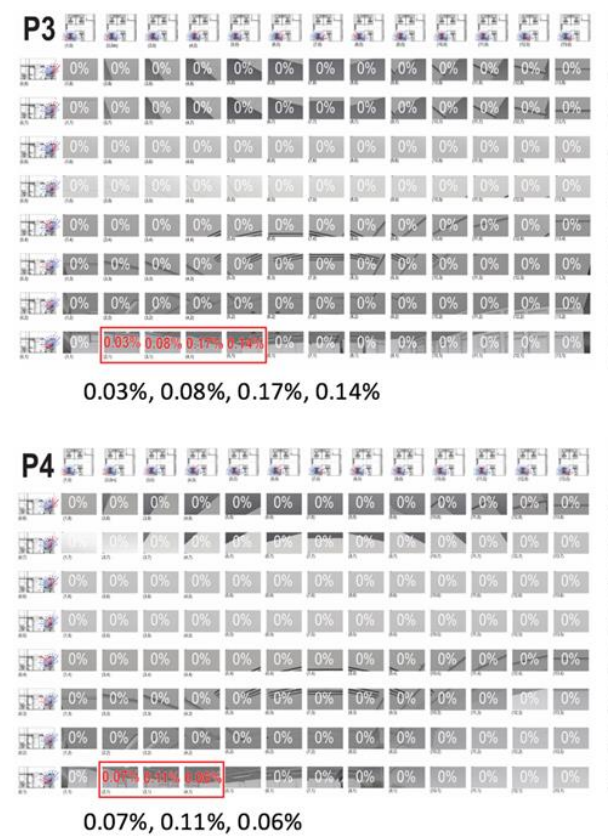

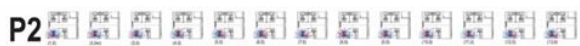

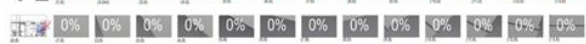

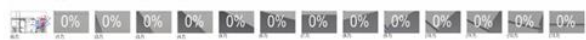

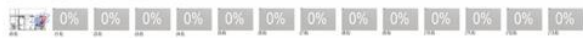

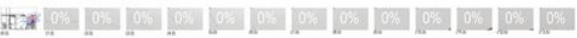

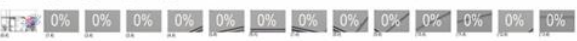
This

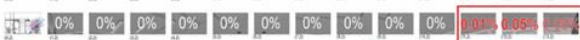

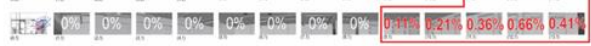
$0.01 \%, 0.05 \%, 0.05 \%$ $0.11 \%, 0.21 \%, 0.36 \%, 0.66 \%, 0.41 \%$

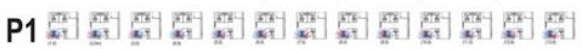

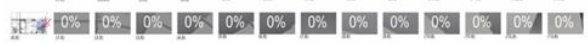
Jix

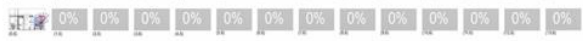

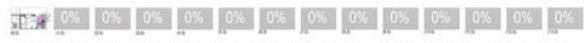

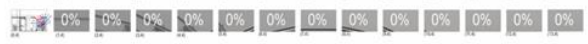

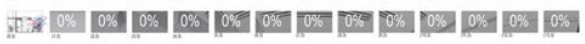

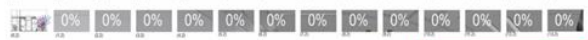

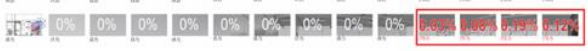

$0.03 \%, 0.08 \%, 0.19 \%, 0.12 \%$

Figure 4. The mapping of patients' visual sphere from four positions Source: Authors, 2019

However, the size of the view area of the openings is different for the four patients' point of view. The largest opening view is from P2 position, which has $1,86 \%$ of opening view area, and the smallest is from $\mathrm{P} 4$ position, which has $0.23 \%$ of opening view area. Meanwhile, P1 and P3 position have $0.42 \%$ and $0.24 \%$ of opening view area respectively. The differences in the size of the view to the opening are determined by the relation between the position of each point of view and the placement of the view area. Although the symmetrical layout should create similar distance from the opposite point of view to the view area, in fact, the symmetrical layout is interrupted by the configuration of space, in which the placement of the patient toilet creates an interruption of view for the patient in P3 and $\mathrm{P} 4$ position.

The opening view area from P1 is $0.42 \%$, which is smaller than the opening view area of $1.86 \%$ from $\mathrm{P} 2$. This is due to the distance from the point of view to the wall with openings. From the opening wall, the distance to P1 position is $6025 \mathrm{~mm}$ while the distance to $\mathrm{P} 2$ is $3751 \mathrm{~mm}$. P2 position has the largest opening view are from all four positions because this point has the smallest distance to the opening elements. Meanwhile, the opening view area from P3 and P4 only slightly differ, which are $0.24 \%$ and $0.23 \%$ respectively. Although there are differences in distance from the point of view to the opening wall, the opening view area is almost similar in those positions due to the interruption of the view by the placement of the patient toilet at the left side of the opening wall. Hence, these two positions similarly experience restricted vision toward the openings. When comparing P3 and P2, which have the similar distance to the opening wall, it can be seen that view to the openings from $\mathrm{P} 3$ is much more restricted than the view from $\mathrm{P} 2$, which are $0.24 \%$ and $1.86 \%$ respectively, as the result of the configuration of space.

The percentage of opening view area within the range of $0.23 \%$ and $1.86 \%$ only represents the parts of the scene that include the opening elements. Further analysis is needed to analyse the regions of elements that incorporate the parts of scenes. Capturing the regions that represent the smaller parts of opening elements is needed to parse the anatomy of the opening element in order to identify the area of opening elements that are visible within the patients' view. 


\subsection{The view of openings from each patient's position}

Figure 5 illustrates the regions that are visible from each of the patient position. The regions are captured from each scene that incorporates the transparent glass doors and windows as the opening elements. The captured images of the regions show the parts of the elements that are included within the range of vision. From position P1 and P2, the patient can
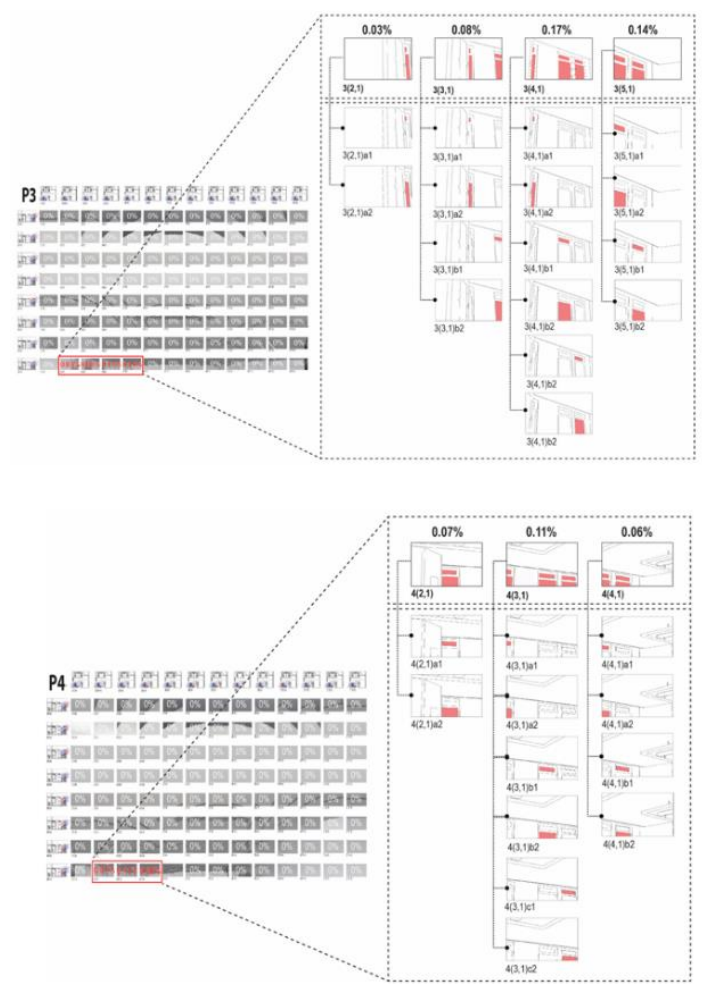

see the openings when moving the eye to the right-downward direction. It can be seen that at the most downward view from the vertical angle of $30^{\circ}-75^{\circ}$, as the eye moves toward the right, the opening element region becomes larger, which means the larger the openings that can be visible. This is also found in P3 and P4, in which the opening elements become larger as the eyes move toward the left.

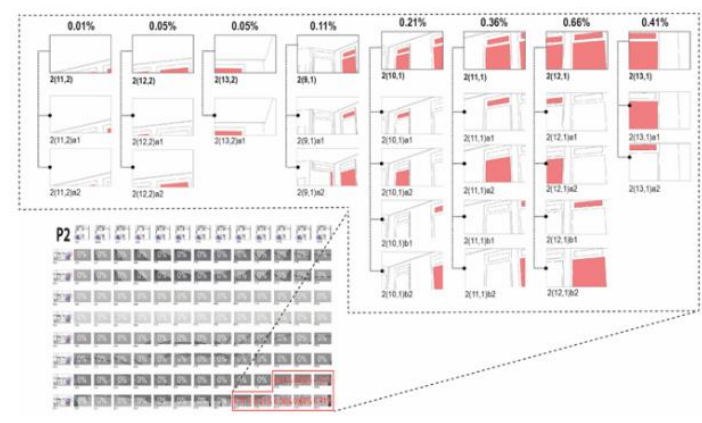

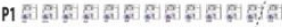

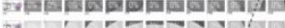
to

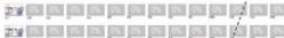

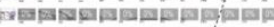
का op

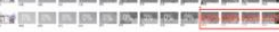

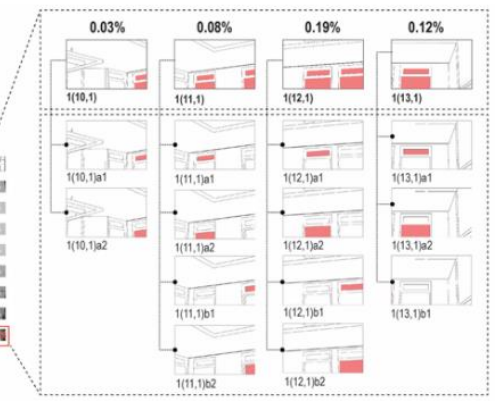

Figure 5. Region of opening view from four patient position (P1-P4) Source: Authors, 2019

Table 1 presents the region area with openings in each scene as the eyes move toward the peripheral; the region area is presented as: (a) the percentage of opening regions from the whole visual sphere; and (b) the percentage of opening regions from each scene. In general, from the four patients' positions, the region areas of the opening elements are the largest in the scene just before the last scene; it shows the scene viewed at $75^{\circ}$ horizontal angle of view, either in lower left peripheral view (in P3 and P4) or the lower right peripheral view (in $\mathrm{P} 1$ and $\mathrm{P} 2$ ). The largest opening region area $20.44 \%$ from $\mathrm{P} 1,67.68 \%$ from $\mathrm{P} 2,17.89 \%$ from $\mathrm{P} 3$ and $11.46 \%$ from $\mathrm{P} 4$, as marked in bold in Table 1 . 
Table 1. Scenes and region area of opening elements in each peripheral view scene.

\begin{tabular}{|c|c|c|c|c|}
\hline Position & $\begin{array}{l}\text { View of } \\
\text { openings }\end{array}$ & $\begin{array}{l}\text { No of scene w/ } \\
\text { openings }\end{array}$ & $\begin{array}{ll}\text { No } & \text { of } \\
\text { subscene } & \text { w/ } \\
\text { openings } & \end{array}$ & $\begin{array}{l}\text { Region area with openings } \\
\text { (a) Percentage of whole visual sphere } \\
\text { (b) Percentage in each scene }\end{array}$ \\
\hline \multirow[t]{2}{*}{ P1 } & \multirow{2}{*}{$\begin{array}{l}\text { Lower right } \\
\text { peripheral }\end{array}$} & \multirow[t]{2}{*}{4 scenes } & \multirow{2}{*}{13 subscenes } & (a) $0.03 \% ; 0.08 \% ; \mathbf{0 . 1 9 \%} ; 0.12 \%$ \\
\hline & & & & (b) $3.45 \% ; 8.82 \% ; \mathbf{2 0 . 4 4 \%} ; 12.51 \%$ \\
\hline \multirow[t]{2}{*}{$\mathrm{P} 2$} & \multirow[t]{2}{*}{$\begin{array}{l}\text { Lower right } \\
\text { peripheral }\end{array}$} & \multirow[t]{2}{*}{8 scenes } & \multirow[t]{2}{*}{21 subscenes } & $\begin{array}{l}\text { (a) } 0.01 \% ; 0.05 \% ; 0.05 \% \\
0.11 \% ; 0.21 \% ; 0.36 \% ; \mathbf{0 . 6 6 \%} ; 0.41 \%\end{array}$ \\
\hline & & & & $\begin{array}{l}\text { (b) } 0.81 \% ; 5.01 \% ; 5 \% \\
10.89 \% ; 21.41 \% ; 36.75 \% ; \mathbf{6 7 . 6 8 \%} \text {; } \\
41.28 \%\end{array}$ \\
\hline \multirow[t]{2}{*}{ P3 } & \multirow{2}{*}{$\begin{array}{l}\text { Lower left } \\
\text { peripheral }\end{array}$} & \multirow[t]{2}{*}{4 scenes } & \multirow[t]{2}{*}{16 subscenes } & (a) $0.03 \% ; 0.08 \% ; \mathbf{0 . 1 7 \%} ; 0.14 \%$ \\
\hline & & & & 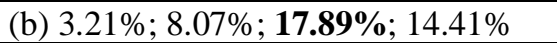 \\
\hline \multirow[t]{2}{*}{ P4 } & \multirow{2}{*}{$\begin{array}{l}\text { Lower left } \\
\text { peripheral }\end{array}$} & \multirow[t]{2}{*}{3 scenes } & \multirow[t]{2}{*}{12 subscenes } & (a) $0.07 \% ; 0.11 \% ; 0.06 \%$ \\
\hline & & & & (b) $7.03 \% ; \mathbf{1 1 . 4 6 \%} ; 5.89 \%$ \\
\hline
\end{tabular}

Referring to figure-ground composition, the scene with the largest region area of opening elements shows the domination of opening elements as the figure in the entire composition at that scene. It captures the opening elements as the figure both in the scenes before and after that particular scene. Meanwhile, in the scene with less region area of opening elements, the scene is dominated by other elements as the ground. The region division explains the role of the region as a figure and as a part of the whole visual composition. The opening elements of the doors and the windows are not unified. Each element consists of several regions, and each region suggest a view to the outside that is not continuous but interrupted because of the limited scope of the region area. Therefore, each region has a different capacity in presenting the outdoor view.

The results also indicate the different distribution of the scenes with opening elements within the whole visual sphere. The scenes with openings are present within the right peripheral view at the range of $45-105^{\circ}$ for $\mathrm{P} 1$ and $30-105^{\circ}$ for $\mathrm{P} 2$, which is at the limit of the peripheral view. Meanwhile, the scenes with openings are present within the left peripheral view at the range of $30-90^{\circ}$ for $\mathrm{P} 3$ and $45-90^{\circ}$ for $\mathrm{P} 4$. This difference in this distribution seems to be related to the difference in the distance to the opening wall, and eventually related to the number of scenes and subscenes as well as the size of region areas that incorporate the opening elements.

The number of scenes illustrates the capturing of the opening elements of doors and windows from the four position. P2 position captures the largest size of the opening elements, which comprises upper half parts of the doors and windows; this is possible due to the closer distance to the opening wall. On the other hand, position P3, which has the similar distance to the opening wall, capture less area of openings, due to the interruption by the toilet element. For the positions with further distance from the opening wall, P1 and P4, both only capture the relatively smaller size of opening elements, which is only the upper part of the door and windows.

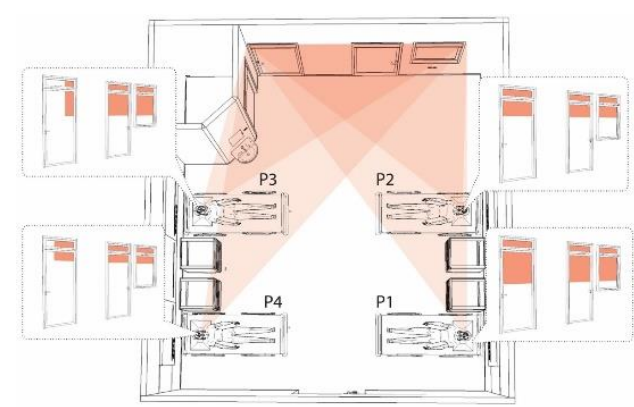

Figure 6. The region areas of opening elements visible from the four patient's point of view

Source: Authors, 2019

\section{DISCUSSION}

This study explores the patients' visual experience of the openings through the seeing mechanism, which explains the visual experience that consists of foveal and peripheral vision (Remington \& Remington, 2012). The foveal view captures the details of the space (Dagnelie, 2011) it describes the area as encoding features 
of the visual environment, particularly the features or elements depicting spatial layouts. Meanwhile, the peripheral view represents the spatial visual context and allows the observer to relate to the surrounding (Pallasmaa, 2012). This study argues the thought of Pallasmaa that experiencing architectural space occurs only by the unfocused peripheral vision. In fact, the peripheral view can not occur without the focus view. It is the movement of the foveal vision that creates the sequences of the visual surface in one's visual experience. Through a series of scenes of the movement of foveal vision, we can appreciate the context of the whole visual environment represented by the peripheral view. If we only consider our experience from one peripheral point of view, we miss the experience of space in recognizing parts clearly in a more detailed context.

The openings in the inpatient ward are expected to offer the benefits for the patients' healing process as argued by previous research on windows in the healthcare environment (Chen, 2014; Helphand, 2019; Ulrich, 1984; Ulrich et al., 2008). However, this study found that the openings are only partially included within the patient's peripheral view range. There are no opening areas within the foveal view. This suggests that the patients have the incomplete visual experience of the openings and unable to perceive the openings as the focus in seeing. Moreover, only the upper parts of the openings are visible from the position of the patients. The placement of the openings that are only partially seen does not allow the observer to comprehend the relationship of the parts of the interior (Bekkering et al., 2008). Thus the presence of the openings in the inpatient room does not automatically provide the view to the outdoor environment needed by the patients.

The visual experience as illustrated in this simulation occurs due to the condition of patients lying on the bed. The limited visual capacity of the patients in the bedridden condition is related to the position and orientation of the patient's point of view, the distance from the openings and the configuration of opening elements as well as the potentially visually disrupting elements. The findings suggest the discrepancies between the designer's perspective in the placement of the doors and windows as the opening area and the perspective of the patient in experiencing space. From the designer's perspective, the connection between the inside and outside is understood by seeing the space as a whole, which incorporates the openings. This seems to be based on the assumption on the experience of space in the normal standing position with the optimum visual capacity to cover most parts of space and space elements. However, from patient's perspective, the patient can not experience the view through the openings as intended by design due to the limitation of the visual experience, in which the openings are located within the peripheral view.

\section{CONCLUSION}

This study simulates the patient' visual experience of the openings in the inpatient ward by identifying the scenes containing opening elements as captured from four patient's positions. It reveals the limited view toward the openings from the patients' point of view, which is only within the range of $0.23-1.86 \%$ located in the peripheral view range of the whole visual sphere. The result indicates that the patients could only view the openings in their peripheral view range, and no openings are present within the foveal view range. The opening elements that are within the view are only partial, which suggests the incomplete experience of the view through the opening. The limitation of patient's view of the opening elements is related to several factors, such as the distance from the patient's point of view to the opening wall, the angle of view, and the configuration of space.

The findings of this study indicate the limitation in the visual capacity of the patient in seeing the openings, which are only partially visible within the range of the peripheral view. This suggests the discrepancies between the placement of the door and windows openings and the patient's visual experience while being in bedridden condition. The findings raise a question on the role of openings in supporting the healing process of the patients when the placement does not consider the point of view of the patients. This study emphasises on the importance to understand the patient's seeing capacity in experiencing the elements of space in the healing environment. The patient seeing experience, in particular the ability to access the view to the outdoor, becomes essential in promoting the healing process. The limitation of view from the patient's position should be anticipated in the design of interior space layout and interior elements. 
Further research needs to consider exploring the areas that can provide the optimal viewing experience for patients. This needs to become the basis for the placement of the openings to ensure the presence of outdoor view within the patients' foveal range of view, to promote the patient's ability to adapt to the environment while being in the bedridden condition. Understanding the relationship between patient's view and the environment is important for paradigm shifting, from designing based on the arrangement of interior elements (including the placement of openings) to designing based on the patient's seeing experience of the surrounding. In this way, the design of the interior could contribute more meaningfully to the patients' healing process.

\section{ACKNOWLEDGMENT}

This study was funded by PDUPT Research Grant 2017-2018 from the Ministry of Research, Technology and Higher Education of the Republic of Indonesia.

\section{REFERENCES}

Alam, S. M. J., \& Shari, Z. (2019). Occupants interaction with window blinds in a greencertified office building in Putrajaya, Malaysia. Journal of Design and Built Environment, 19(1), 60-73.

Artal, P. (Ed.). (2017). Handbook of visual optics. CRC Press.

Bekkering, H., ten Doeschate, A., Hauptmann, D., den Heijer, A., Knaack, U., \& van Manen, S. (Eds.). (2008). The Architecture Annual 2006-2007. Delft University of Technology. 010 Publishers, Rotterdam.

Cervinka，R.，Röderer，K.，\& Hämmerle, I. (2014). Evaluation of hospital gardens and implications for design: Benefits from environmental psychology for architecture and landscape planning. Journal of Architectural and Planning Research, 31(1), 43-56.

Chen, C. (2014). Impact of nature window view on high school students stress recovery. University of Illinois.

Chua, S. H., Perrault, S. T., Matthies, D. J. C., \& Zhao, S. (2016). Positioning glass: Investigating display positions of monocular optical see-through headmounted display. Proceedings of the Fourth International Symposium on Chinese, 1-6. https://doi.org/10.1145/2948708.2948713
Dagnelie, G. (Ed.). (2011). Visual prosthetics: Physiology, bioengineering, and rehabilitation. Springer.

Handel, S. (2019). Perceptual organization: An integrated multisensory approach. https://doi.org/10.1007/978-3-319-96337-2

Helphand, K. (2019). Prescribing the outdoors. SiteLINES: A Journal of Place, 15(1), 1012.

Herman, I. P. (2007). Physics of the human body. Springer.

Hitzel, E. (2015). Effects of peripheral vision on eye movements. Springer Fachmedien Wiesbaden. https://doi.org/10.1007/978-3658-08466-0

Hunter, M. R., Gillespie, B. W., \& Chen, S. Y.-P. (2019). Urban nature experiences reduce stress in the context of daily life based on salivary biomarkers. Frontiers in Psychology, 10, 722. https://doi.org/10.3389/fpsyg.2019.00722

Hussein, H. (2009). Sensory garden in special schools: The issues, design and use. 5, 7795.

Ishiguro, Y., \& Rekimoto, J. (2011). Peripheral vision annotation: Noninterference information presentation method for mobile augmented reality. Proceedings of the 2nd Augmented Human International Conference, 1-5. https://doi.org/10.1145/1959826.1959834

Jamaludin, A. A., Hussein, H., \& Tahir, K. M. (2018). Satisfaction of residents towards internal courtyard buildings. Journal of Design and Built Environment, 18(2), 6169.

Johanes, M., \& Yatmo, Y. A. (2018). Application of visibility analysis and visualisation in hospital wayfinding sign design. DIMENSI (Journal of Architecture and Built Environment), 45(1), 1-8. https://doi.org/10.9744/dimensi.45.1.1-8

Johanes, M., Yatmo, Y. A., \& Atmodiwirjo, P. (2015). The use of computational medium for visualization and simulation in healthcare architectural design. CONMEDIA 2015 - International Conference on New Media 2015. https://doi.org/10.1109/CONMEDIA.2015. 7449142

Kleine, H. (2018). The drama of space: Spatial sequences and compositions in architecture. Birkhäuser.

Kubovy, M., \& Pomerantz, J. R. (Eds.). (2019). Perceptual organization. Routledge. 
Levin, L. A., Siv, F. E. N., James, V. H., Wu, S., Kaufman, P. L., \& Alm, A. (Eds.). (2011). Adler's physiology of the eye: Clinical application (11th ed). Saunders/Elsevier.

Lyons, T., \& Carhart-Harris, R. L. (2018). Increased nature relatedness and decreased authoritarian political views after psilocybin for treatment-resistant depression. Journal of Psychopharmacology, 32(7), 811-819. https://doi.org/10.1177/0269881117748902

Malek, N. A., Mohammad, S. Z., \& Nashar, A. (2018). Determinant factor for quality green open space assessment in Malaysia. Journal of Design and Built Environment, 18(2), 26-36.

Olver, J., Cassidy, L., Crawley, L., \& Jutley, G. (2014). Ophthalmology at a glance (2nd ed). John Wiley \& Sons.

Orbon, G. T., Sarte, G. Ma. F., Montero, C. I. V., \& Abelardo, R. S. B. (2019). Characterizing campus open spaces of University of the Philippines Diliman based on utilization and perception of outdoor thermal comfort. Journal of Design and Built Environmen, 19(2), 74-90.

Ozdemir, A. (2010). The effect of window views' openness and naturalness on the perception of rooms' spaciousness and brightness: A visual preference study. Scientific Research and Essays, 5(16), 2275-2287.

Pallasmaa, J. (2012). The eyes of the skin: Architecture and the senses. WileyAcademy; John Wiley \& Sons.

Rainey, R. M. (2019). Design for healing. SiteLINES: A Journal of Place, 15(1), 3-5.

Remington, L. A., \& Remington, L. A. (2012). Clinical anatomy and physiology of the visual system (3rd ed). Elsevier/Butterworth Heinemann.

Sengke, M. M. C., \& Atmodiwirjo, P. (2017). Using isovist application to explore visibility area of hospital inpatient ward. IOP Conference Series: Materials Science and Engineering, 185, 012008. https://doi.org/10.1088/1757899X/185/1/012008

Sengke, M. M. C., Atmodiwirjo, P., \& Yatmo, Y. A. (2018). The configuration of window placement and spatial arrangement based on patient's seeing capacity. IOP Conference Series: Earth and Environmental Science, 195, 012098. https://doi.org/10.1088/17551315/195/1/012098
Suter, P. S., \& Harvey, L. H. (2016). Vision rehabilitation: Multidisciplinary care of the patient following brain injury. CRC Press.

Turner, A., Doxa, M., O’Sullivan, D., \& Penn, A. (2001). From isovists to visibility graphs: A methodology for the analysis of architectural space. Environment and Planning B: Planning and Design, 28(1), 103-121. https://doi.org/10.1068/b2684

Ulrich, R. S. (1984). View through a window may influence recovery from surgery. Science, 224(4647), 420-421. https://doi.org/10.1126/science.6143402

Ulrich, R. S. (1993). Biophilia, biophobia, and natural landscapes. Biophilia, Biophobia, and Natural Landscapes, 73-137.

Ulrich, R. S., Zimring, C., Zhu, X., DuBose, J., Seo, H.-B., Choi, Y.-S., Quan, X., \& Joseph, A. (2008). A review of the research literature on evidence-based healthcare design. HERD: Health Environments Research \& Design Journal, 1(3), 61-125. https://doi.org/10.1177/1937586708001003 06

Vall, R. van de, \& Zwijnenberg, R. (Eds.). (2009). The body within: Art, medicine and visualization. Brill.

Walsh, T. J. (Ed.). (2011). Visual fields: Examination and interpretation (3rd ed). Oxford University Press.

Waroonkun, T. (2018). The environmental factors affecting service satisfaction of community hospital. Journal of Design and Built Environment, 18(1).

Weigel, S., \& Paul, G. (2003). Body-and imagespace: Re-reading Walter Benjamin. Routledge.

Yildirim, K., Akalin-Baskaya, A., \& Celebi, M. (2007). The effects of window proximity, partition height, and gender on perceptions of open-plan offices. Journal of Environmental Psychology, 27(2), 154-165. https://doi.org/10.1016/j.jenvp.2007.01.004

Yuniati, A. P., Wardono, P., \& Maharani, Y. (2018). The impact of natural element's forms in emergency unit room toward nurse motivation and attitude during night shift: Case of Santo Borromeus Hospital. Journal of Design and Built Environment, 18(2), 46-60. 